\title{
El concepto de toque flamenco
}

\author{
Norberto Torres Cortés \\ Doctor en Ciencias Sociales y Humanas
}

Enviado: $16-12-2020$

Aceptado: 22-12-2020

\section{Resumen}

Este artículo contiene el primer capítulo de la tesis doctoral que defendimos en 2009 (Torres, 2009). No ha sido publicado hasta ahora y, a pesar del tiempo transcurrido y de algunos aspectos parciales ampliamente desarrollados desde su redacción, así como una bibliografía consultada hasta este año 2009, pensamos que sigue vigente al reunir elementos filológicos, culturales y musicales que permiten una mayor comprensión y perspectiva del concepto "toque flamenco". Hemos articulado estos tres elementos en torno a dos ejes: por una parte, el concepto de "toque flamenco" (que es igual a preguntarse qué entendemos por guitarra flamenca); por otra parte, cuáles son los rasgos significativos y apropiados de esta modalidad guitarrística.

Palabras clave: guitarra flamenca, toque flamenco, tocaor.

\section{Abstract}

This article contains the first chapter of the doctoral thesis that we defended in 2009 (Torres, 2009). It has not been published until now and, despite the time that has elapsed and some partial aspects widely developed since its writing, as well as a bibliography consulted until 2009, we think that it can continue to be valid by offering philological, cultural and musical elements that allow a greater understanding and perspective of the concept of "toque flamenco". We have articulated these three elements around two axes: the concept of "toque flamenco" (which is the same as wondering what we mean by flamenco guitar); and what are the significant and appropriate features of this guitar modality. 


\section{El concepto de "toque flamenco"}

Dentro del contexto cultural de los aficionados del flamenco y de la guitarra, es común llamar a la guitarra flamenca "toque flamenco". En un reciente diccionario de términos del flamenco, en la voz "toque" se nos dice que:

Todo lo referido a la guitarra flamenca se engloba en el término genérico toque flamenco. Cada uno de los toques se basan en los principios concretos que definen un estilo determinado; así, el toque por tangos está referido a los acordes y los recursos técnicos que se utilizan en la interpretación a la guitarra de los tangos flamencos. También se utiliza esta palabra para referirse al tipo de toque que se realiza, el toque a compás, para los estilos que se basan en una métrica determinada, y el toque libre, para aquellos que se interpretan sin un metro concreto, sino con una rítmica libre concertada entre guitarrista y cantaor (Gamboa y Núñez, 2007: 571)ํ․

Sobre el término genérico "toque flamenco", nuestra experiencia como guitarrista entre los aficionados y profesionales de este género musical nos ha confirmado que con ello se da por supuesto, en base a la tradición, que la función de esta guitarra es la de acompañar el cante y el baile, considerando como "otra cosa aparte" la guitarra solista. Vemos por consiguiente que la propia definición/del concepto "toque flamenco" alude a la función armónica ("acordes") y rítmica ("recursos rítmicos") de la guitarra flamenca. Entenderemos pues por "toque flamenco" la función de acompañamiento de la guitarra flamenca, y por "toque solista" su utilización para concierto.

Vamos a describir a continuación los rasgos técnicos y musicales característicos del toque flamenco. Esta descripción ha sido elaborada a partir

\footnotetext{
${ }^{1}$ Anteriormente, José Blas Vega y Manuel Ríos Ruiz definieron la voz "toque" en su Diccionario enciclopédico ilustrado del flamenco: «[de tocar.] Acción y efecto de tañer la guitarra flamenca. // 2. Palmeo, son o golpeo acorde que se hace con las palmas de las manos para seguir los distintos ritmos del cante o baile flamencos. // 3. Cada una de las diversas maneras de acompañar musicalmente un cante o un baile flamencos. // 4. Pieza o número musical a la guitarra flamenca. // 5. Por extensión, sonido o tono peculiar o también estilo propio de cada tocaor» (Blas Vega y Ríos Ruiz, 1987: 757).
} 


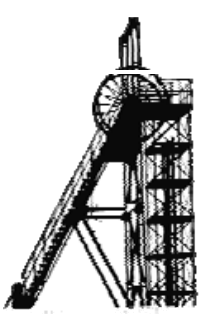

de nuestra larga experiencia como "tocaor", es decir guitarrista flamenco ${ }^{2}$, con la que hemos podido observar y reflexionar sobre esta práctica (observación emic). A ello se une una no menos larga experiencia didáctica durante la que hemos enseñado esta práctica, con la que hemos tenido que ordenar y graduar nuestro discurso pedagógico, de manera a transmitir razonablemente a nuestros alumnos el resultado de nuestro aprendizaje y reflexión. Esta descripción concierne ahora la categoría estética que llamamos "lo clásico" dentro del toque, es decir una serie de reglas técnicas y musicales establecidas como código por los artistas y profesionales, y por ello asumido por los aficionados, que define el canon estético de la guitarra flamenca desde su aparición, más o menos a mitad del siglo XIX, hasta los años 70 del siglo XX. Es entonces cuando una nueva generación de profesionales, desde una nueva función en solista del instrumento, liderará una corriente musical estética que volverá a definir estas reglas con un nuevo código para otra categoría estética que llamamos "lo contemporáneo" (Torres, 2004).

\section{Parámetros musicales del toque: el ritmo}

La guitarra flamenca se fundamenta en tres parámetros musicales: melódico, rítmico y armónico. Según nuestra hipótesis de trabajo, estos

\footnotetext{
2 Miguel Ropero lo recoge como equivalente a "guitarrista flamenco" e indica que «es un término característico y específico del flamenco; dentro de este lenguaje especial adquiere su auténtico valor significativo y en él ha adquirido, incluso, una fonética y grafías peculiares. Despojarlo de estas características fonéticas o gráficas y pronunciarlo o escribirlo según la normativa del castellano, supondría sacarlo de su propio sistema e introducirlo en un sistema extraño, donde pierde su valor expresivo. Porque un tocaor no es un "tocador" (que sería un mueble) ni tampoco un "guitarrista" simplemente sino un "guitarrista flamenco». El lexema tocaor tiene un rasgo semántico específico: 'flamenco', que no tiene el lexema guitarrista" (Ropero, 1983: 216). Gamboa y Núñez también inciden en esta definición recientemente: «Suele emplearse tal denominación, frente a la de guitarrista, más amplia, para referirse al acompañante, mientras que la otra queda para el concertista» (Gamboa y Núñez, 2007: 561). Sin embargo, ambas no recogen una realidad reciente del flamenco, la de los concertistas de guitarra flamenca, quizá por la novedad de esta disciplina en este género musical, de allí la resistencia de los aficionados en reconocer a la guitarra flamenca de concierto como parte de la cultura flamenca.
} 
parámetros ya estaban presentes de manera elemental en el "toque", es decir en sus tradicionales funciones de acompañamientos de danzas y cantos.

El melódico se desarrolla dentro del concepto de "heterofonía" que caracteriza el acompañamiento del cante flamenco, es decir un ligero adorno melódico que completa la melodía del cante a modo de respuesta orientativa y que los aficionados suelen llamar "contrapunto", sin que este término tenga relación con el contrapunto de la música polifónica. El rítmico se desarrolla dentro del concepto de "compás", es decir de los ciclos rítmicos característicos de la música flamenca.

El armónico se desarrolla dentro de los conceptos de modalidad y tonalidad, es decir como fondo sonoro de acordes en modo de $\mathrm{Mi}$ o/y en tonalidades mayor y menor, siguiendo las inflexiones de la melodía del cante 3 .

3 La teoría musical sobre flamenco es bastante reciente. Por regla general, los estudios musicológicos sobre el flamenco son también escasos. Ya en 1975 Arcadio de Larrea se quejaba de que "es de suma importancia el análisis de la técnica musical del cante por musicólogos especializados. Este capítulo, tan vital para el estudio de los orígenes y evolución de los distintos estilos flamencos, está casi inédito, pues muy pocos han sido los musicólogos preparados e interesados por el tema. Salvo algunos escarceos de Felipe Pedrell, sólo contamos con la labor -escasa pero positiva- del profesor García Matos" (Larrea, 1975: 8). Recientemente al hacer la recensión de forma ordenada de las publicaciones sobre flamenco, la antropóloga Cristina Cruces también indicaba en un párrafo titulado significativamente "El estudio musical del flamenco, asignatura pendiente en la investigación" que "Al estar lejos de las claves técnicas y los procedimientos de estudio de las "músicas cultas", y en particular de las tradiciones de música occidental, la paradoja es que esta música -incluso si se entendiera el flamenco en esta única acepción- no fue ni tan siquiera abordada con los recursos de notación, transcripción y ordenación propiamente musicológicos. Si entre los músicos no flamencos no ha existido apenas interés por unas formas y unas estructuras armónicas, melódicas y rítmicas de clara filiación oriental, entre los intérpretes del género pocos han sido a la vez sujetos investigadores de su propia música" (Cruces, 2000: 403). Cuando escribía su recensión, aún no se había publicado Sobre la guitarra flamenca. Teoría y sistema para la Guitarra flamenca de Manolo Sanlúcar (2005), un hito en la bibliografía flamenca, ya que por primera vez un artista del género reflexionaba y teorizaba musicalmente sobre su propia música, aunque el contenido sea discutible. Sobre la teoría musical sistemática, dos obras recientes han sido publicadas, con perfiles bien distintos. Faustino Núñez es autor del libreto Comprende el flamenco (2003), guía divulgativa sobre los aspectos musicales del flamenco para el gran público, elaborada a partir del artículo que publicó en Tartessos (1996). Para el alumnado de los Conservatorios, Lola Fernández publicó en 2004 su Teoría Musical del Flamenco. La antropóloga musical del Conservatorio Liceu de Barcelona, María Jesús Castro, publicó, por su parte, la Historia musical del flamenco (2007). 


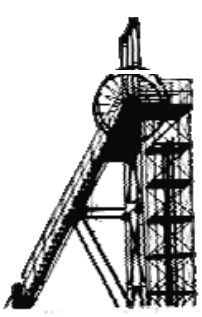

El "tocaor" pues, es decir él que acompaña el cante o el baile, tiene que controlar en permanencia estas tres funciones: mantener el compás, dar respuestas al cante o al baile, armonizarlos. De allí que el aprendizaje de la guitarra flamenca requiera tiempo y práctica, no sólo para adquirir los reflejos de digitaciones o "mecánica", sino para aprender a simultanear estas funciones, de preferencia en contextos afines, como son el entorno del cante y del baile. Alcanzan su grado más intenso de virtuosismo en el llamado "toque pa cante", donde el guitarrista tiene que mantener el ritmo, contestar los "tercios" o frases musicales del cante y armonizar con un fondo sonoro adecuado la melodía del cante, sin apoyos externos como pueden ser las palmas o percusiones que el baile propone, y además estar pendiente del cantaor para ayudarle en su interpretación.

No es una casualidad si la mayoría de los concertistas actuales insistan en estas funciones de la guitarra flamenca cuando especifican que antes de ser solista hay que dominar los acompañamientos del cante y del baile.

Para perfeccionar estas funciones, los guitarristas "por lo flamenco" o "tocaores" se han valido de varios recursos técnicos y musicales: en el aspecto rítmico por ejemplo una sofisticada técnica de baterías rítmicas llamadas "rasgueos" o "rasgueados" que da gran parte de la llamada "sonoridad flamenca", golpes en la tapa, un virtuoso toque de pulgar que también define la "sonoridad flamenca", además con una elaborada utilización como plectro llamada "alzapúa", en el melódico, el apoyado en escalas y melodías con el pulgar o con los dedos índice-medio alternando ("picado"), trémolo de cuatro notas, ligados abundantes en la mano izquierda, en lo armónico posiciones de acordes perfectos, "imperfectos" y de séptimas sobre la cadencia andaluza, enriquecidas por cuerdas al aire y más tarde por posiciones invertidas y otras incorporadas con el contacto con otros géneros musicales, especialmente con la bossa-nova y el jazz, en la mano derecha todas clases de arpegios. 
Si tuviéramos que fijar un orden de importancia en estas funciones, el rítmico aparecería en primer lugar, ya que condiciona los demás ${ }^{4}$. Lo podemos observar si comparamos la guitarra clásica con la flamenca. Esta última ha incorporado varios recursos de la primera, pero los ha hecho suyo desde su vocación rítmica: apoyado en las escalas, trémolo de cuatro notas, más rítmico y brillante, en lugar del trémolo de tres notas de la guitarra clásica, más lírico y nítido, omnipresencia del índice de la mano derecha en la primera o segunda cuerda, dedo que alternando con el pulgar permite sentir mejor la pulsación rítmica, etc. Son por consiguiente las técnicas de mano derecha las que primero darán a la guitarra flamenca su particularidad idiomática, lo que los aficionados llaman coloquialmente "sello". Conviene entonces detenernos en la posición de esta mano.

\subsection{La mano derecha}

Cuando imparto mis clases de guitarra flamenca, como en cualquier clase de instrumento, trato primero de la colocación de las manos. Empezamos por la mano derecha e indico a los alumnos - varios tienen una previa formación clásica- que la gran diferencia entre la guitarra clásica y la guitarra flamenca reside en que esta última tiene puntos de apoyo en la tapa armónica y en las cuerdas, y sabe siempre donde está, a diferencia de la primera que alterna puntos de apoyo en las cuerdas con movimientos en los que la mano está suelta. Los puntos de apoyo en la guitarra flamenca, para colocar la mano desde el principio, son el dedo anular y medio en la tapa armónica, el pulgar en la sexta cuerda y el índice en la primera. Aunque Rafael Marín escribía en su método, (publicado en 1902, el Único publicado de aires andaluces y único en su género como

\footnotetext{
4 El concertista Juan Manuel Cañizares comentó en un curso de verano de la Universidad Internacional Menéndez Pelayo que «el carácter rítmico caracteriza la guitarra flamenca por antonomasia. Muchas veces he comentado que me atrevería a calificarlo como un instrumento de percusión más (negritas suyas). Cuando es solista acompaña al baile y en conjunto sirve de referencia para marcar el ritmo. Sin sentido del ritmo es imposible tocar bien la guitarra flamenca» (recuperado de www.esflamenco.com, 10/08/2009).
} 


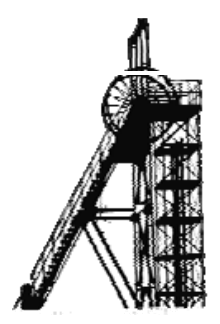

señalaba como reclamo publicitario) que «en el género andaluz no hay ni hubo jamás escuela de manos, sino que cada uno la ha colocado como ha podido o sabido» (Marín, 1902/1995: 24), y que Gerardo Núñez (2004) vuelve a decir lo mismo en sus recientes comentarios introductorios a su técnica guitarrística ${ }^{5}$, aunque cada uno la coloque en función de su fisiología, se puede observar que estos puntos de apoyo ya determinan una colocación y una escuela, la de guitarra flamenca ${ }^{6}$. ¿Porqué estos puntos de apoyo previos? Muy sencillo. Como la mano derecha va a usar la madera del instrumento de forma percusiva7, se prepara para ello: los dedos anular o anular/medio golpearán en la tapa armónica con las uñas. Este uso percusivo de la guitarra es sumamente importante, ya que de antemano obliga al guitarrista flamenco a tocar con uñas. Sin las uñas es casi imposible golpear en la tapa, el sonido de la yema siendo sordo y casi inaudible. El sonido flamenco por consiguiente será entre otras características el de guitarra producido con uñas. Además, al tener el dedo anular y el medio apoyados en la tapa, los que nos quedan para pulsar las cuerdas son el pulgar en la sexta para los bordones, y el índice apoyado en la primera. No es una casualidad si las falsetas o variaciones melódicas más antiguas de los "tocaores" se ejecutan con la única utilización del pulgar, o con el pulgar alternando con el índice. El pulgar asumirá pues el parámetro

\footnotetext{
${ }^{5}$ Este adjetivo no aparece en los diccionarios de uso del español, y es utilizado con frecuencia en los tratados y libros que tratan sobre guitarra, designando lo relativo a este instrumento.

${ }^{6}$ Comentando primero la técnica de pulgar como característica de la guitarra flamenca, aconseja colocar la mano con "la posición más natural y relajada" sin más precisiones, aunque observando la imagen mientras utiliza el pulgar, vemos el punto de apoyo del índice en la prima y los dedos medio e índice preparados para golpear. Más adelante, explicando la técnica de picado, nos dice "Los picados. ¿Cómo colocar la mano? Pues yo después de tantos años tocando la guitarra, no me atrevería a decir cómo la pongáis, sino simplemente ponerla, porque lo importante es lo que suena".

7 Otro neologismo que no aparece en los diccionarios de uso del español. Adjetivo que designa la utilización de un instrumento armónico como percusión. Manuel Ramada nos dice que «H. Cowell fue uno de los primeros compositores en usar estos efectos llamando piano percusivo en su obra The Leprechaum (1925)» (Ramada, 2000: 69). Otros compositores contemporáneos que han utilizado después el piano como recurso percusivo son Ligeti, Crumb y Cage. Nosotros lo aplicamos ahora a la utilización de la guitarra como percusión armónica.
} 
melódico en la técnica de mano derecha, adornado también con la alternancia del dedo índice en la primera cuerda, y a veces la segunda.

Este uso como percusión del instrumento determina también el lugar donde se coloca la mano derecha. Para conseguir efecto rítmico y buena pulsación, es necesario que las cuerdas tengan mayor tensión. Las de la guitarra presentan entre otras propiedades la de estar muy tensas cerca del puente, y perder esta tensión conforme vamos subiendo la mano hacia la boca, alejándola del puente. Además, para golpear cómodamente en la tapa armónica con los dedos medio y anular, resulta indispensable poner la mano entre el puente y la boca. El guitarrista flamenco colocará la derecha por consiguiente cerca del puente, de manera a tener la tensión adecuada en las cuerdas y obtener la necesaria pulsación rítmica, además de poder golpear sin problema en la tapa armónica. Esta colocación de la mano cerca del puente tendrá por otra parte incidencia en la característica musical del sonido flamenco. En efecto, la guitarra tiene la particularidad de presentar una variada paleta sonora, en función de la posición de la mano derecha. Será más agudo, percutido y metálico cuanto más cerca del puente, y dulce, redondo y cálido conforme subiremos esta mano hacia la boca y más allá, hasta conseguir el llamado "sonido de arpa", posicionándola ya fuera de la boca en los últimos trastes.

La tensión de cuerda es además necesaria para ejecutar con eficacia y brillantez una de las especificidades del toque flamenco, el rasgueado. Entre las técnicas de mano derecha como procedimiento idiomático que determina el uso rítmico del instrumento, resulta fundamental. Su anotación y utilización en obras orquestales ha sido sintomáticamente uno de los recursos predilectos en compositores que se han acercado a la guitarra flamenca, entre ellos el gaditano Manuel de Falla (Cristoforidis, 1993). Obedece según nuestra hipótesis a la función de acompañamiento de danzas y cantos de la guitarra popular, que luego seguirán practicando los primeros "tocaores" cuando el género flamenco aparecerá principalmente en el contexto profesional de los cafés cantantes. 


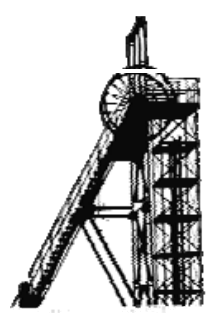

Consideramos de capital importancia este punto, ya que esta función rítmica de acompañamiento con el uso de rasgueados determinará gran parte de la estética y dinámica propia de la guitarra flamenca, que tomará consciencia de su particularidad idiomática precisamente por ello, e incorporará mecanismos y recursos de la guitarra "punteada" o guitarra "clásica" como el arpegio o el trémolo a partir de su vocación rítmica. El uso de la guitarra rasgueada dota en efecto al que la práctica de cierta soltura de mano derecha que se reflejará en otra comprensión rítmica de la música que la que se consigue con la guitarra "punteada" o arpegiada. El guitarrista clásico José Ma Gallardo del Rey escribe en este sentido que:

La técnica de la guitarra flamenca, en cualquiera de sus consideraciones, es un factor importantísimo a tener en cuenta por mí, como guitarrista clásico. La velocidad al servicio del aire, la claridad cristalina de los arpegios, son, por nombrar dos, conceptos que fomentan, consciente o inconscientemente, los perfiles de la musicalidad. El “tener aire" o "tocar con aire" no es más que la pura y auténtica comprensión del ritmo en toda su magnitud, sin hacer sentir la pulsación métrica, como ocurre en la gran mayoría de los intérpretes de corte académico (Gallardo, 1996: 105).

\subsection{Los repertorios locales: criterios rítmicos}

Dada la importancia que tiene el ritmo en el toque flamenco, conviene recordar aquí brevemente, desde una clasificación rítmica, los repertorios flamencos locales de los "tocaores", que hemos reunido en tres grandes familias:

- ritmos con amalgama

- ritmos ternarios

- ritmos binarios

Al primer grupo pertenecen gran parte de las formas localizadas en el valle del Guadalquivir: 
a) El compás de soleá $6 \times 8+3 \times 4$ (con 12 tiempos), que rige otros cantes como la caña, el polo, alegrías y variantes (cantiñas, caracoles, romera, mirabrás), la soleá por bulería, la bulería, la alboreá, la bambera, la petenera, la guajira.

Recordamos el famoso patrón rítmico que los flamencos suelen utilizar para marcar este compás de soleá:

$$
\begin{array}{llllllllllll}
1 & 2 & 3 & 4 & 5 & 6 & 7 & 8 & 9 & 10 & 11 & \mathbf{1 2}
\end{array}
$$

Si tenemos en cuenta que, midiendo a la corchea, este compás se inicia realmente con un silencio, su escritura adecuada sería la siguiente:

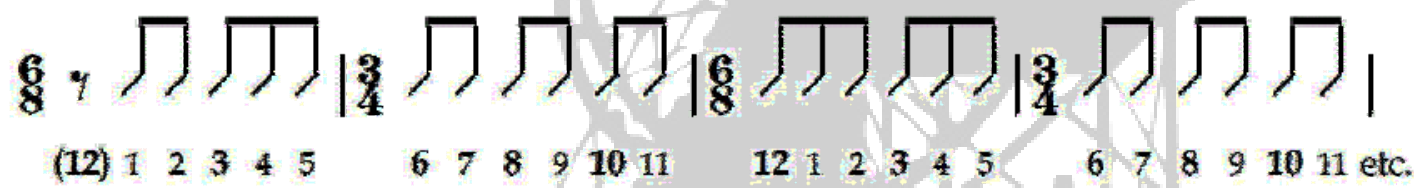

La petenera y la guajira no presentan este inicio sobre un silencio, sino que tendremos la alternancia $6 \times 8+3 \times 4$ con sus acentos respectivos:

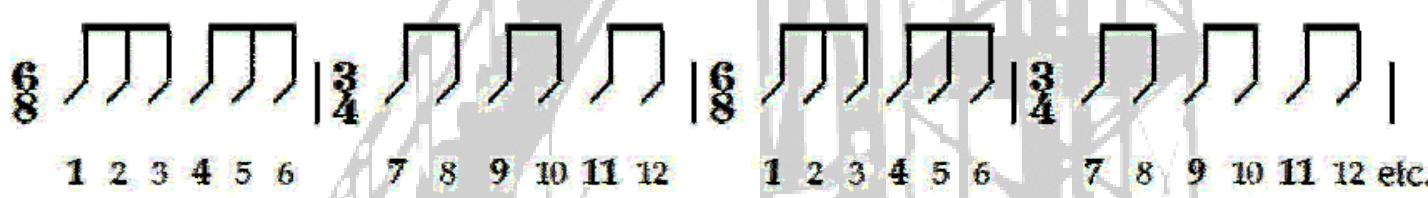

Después de varias formas rítmicas, la bulería presenta hoy la acentuación siguiente, con una síncopa entre el final del 6x8 y el inicio del $3 \times 4$ :

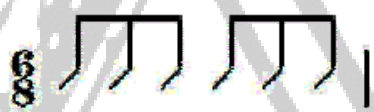

$\begin{array}{llllll}1 & 2 & 3 & 4 & 5 & 6\end{array}$

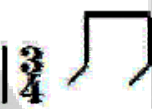

$\begin{array}{llllll}7 & 8 & 9 & 10 & 11 & 12\end{array}$

b) El compás de seguiriya $3 \times 4+6 \times 8$ que rige a su vez otros cantes como la liviana, la serrana, las cabales, el martinete y algunos cantes por "toná".

Este compás también se inicia, midiendo a la negra, con un silencio sobre la primera negra del 3x4, resultando así su métrica: 


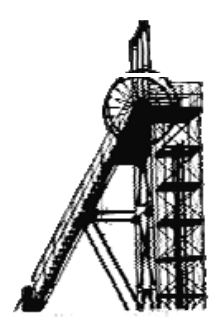
$3+1 \leq$
(6).
$\left|\frac{3}{4}\right|$
161.
). 1
(1) 23
45
123
45 etc.

Al segundo grupo pertenecen gran parte de las formas localizadas en Andalucía Oriental, con el patrón rítmico del fandango como base, con ritmo $3 \times 4$ externo: verdiales, rondeñas, jaberas, jabegotes, fandangos locales, etc.

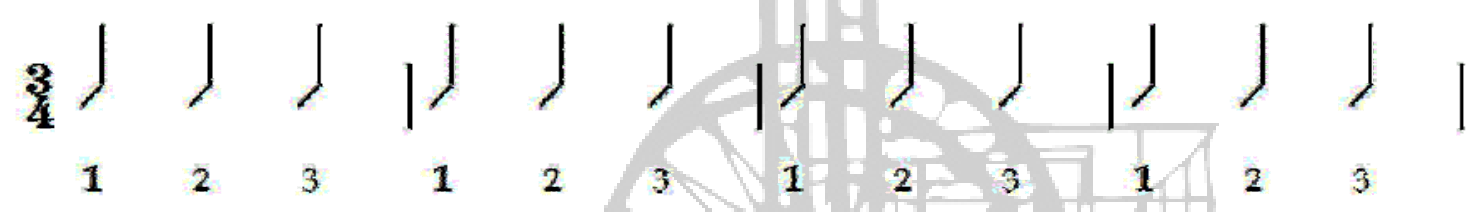

Hasta tal punto el ritmo se ha ralentizado y diluido en este grupo, que ha dado lugar a los llamados "cantes libres", desprovistos de compás, que los flamencos llaman también "ad libitum". A diferencia del primer grupo donde el compás es lo esencial en la expresión musical, en estos cantes de Andalucía Oriental pasará todo lo contrario y se valorará en ellos la expresión lírica. Con ritmo 3x4 interno serán malagueñas, granaína y media granaína, cantes de Levante (tarantas, minera, cartagenera, murciana, levantica, fandango minero, cante del trovo), fandangos artísticos.

Aunque perteneciente a la familia del fandango y por consiguiente ternarios, los fandangos de Huelva recibirán influencia de la soleá en su distribución de acentos a la hora de ejecutarlos con la guitarra, siendo un género mixto y caso aparte en la forma fandango, más cercana a la pulsación rítmica de amalgama, que a la sencilla pulsación ternaria de las formas “abandolás". Es por ello que la correcta ejecución del ritmo de Huelva encerrará cierta dificultad.

Al tercer grupo pertenecen formas localizadas en el valle del Guadalquivir y en el Barrio del Sacromonte de Granada, con el compás de tangos que rige otros cantes como los tientos, la farruca, el garrotín, la colombiana, la rumba, la milonga, la mariana, etc. 


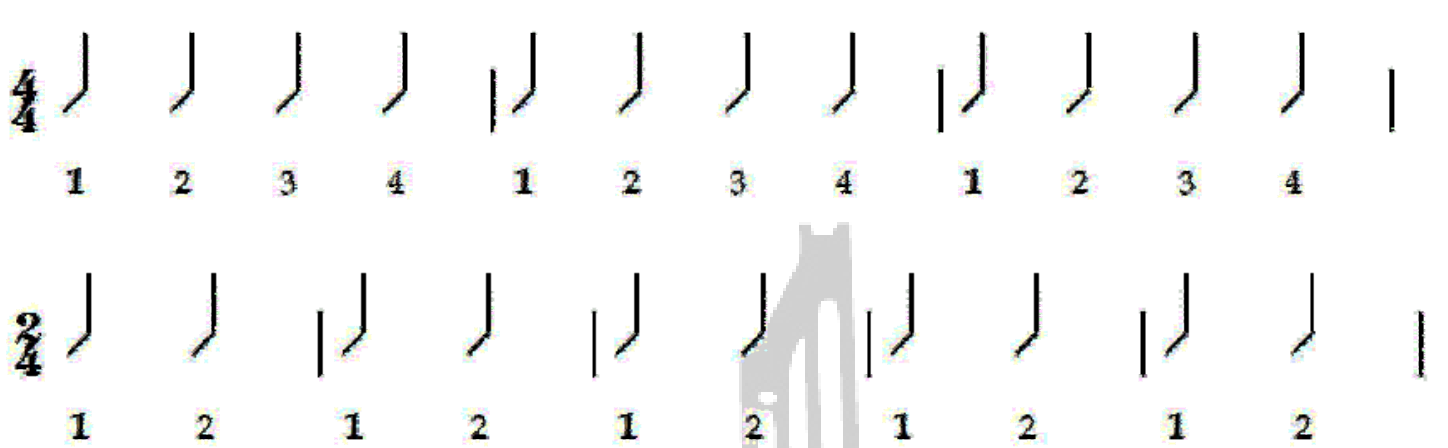

Este último binario de dos tiempos es propio de la zambra, y lo encontramos curiosamente en uno de los fandangos de procedencia levantina, el taranto. Los llamados "tangos de Graná" tienen a menudo también secuencias rítmicas de dos tiempos dentro del patrón rítmico de 4 tiempos de los tangos flamencos, seguramente por ser en parte melodías de zambras adaptadas a tangos flamencos.

Hemos podido oír y leer que muchos aficionados asocian "compás" con "ritmo". "Tiene compás" o "tiene ritmo" son expresiones que usan como sinónimas. Nos apresuramos a señalar que no es así. "Tener compás" en el flamenco es tener bien/interiorizada la distribución de acentos de los particulares compases flamencos de amalgama y expresarlos naturalmente. Se puede tener ritmo y no tener compás, como se ha podido apreciar en varios de los desafortunados encuentros entre músicos flamencos y músicos de jazz organizados sin ton ni son, incapaces los últimos en mantener una sesión común sobre la base rítmica de la bulería.

Por eso podemos decir que, desde una primera lectura territorial, el solar rítmico del flamenco, el de su complejidad y personalidad, el de su "compás", está situado en la parte occidental de la región andaluza, especialmente en la provincia de Cádiz, y el flamenco de expresión lírica en la parte andaluza oriental. 


\section{Parámetros musicales del toque: la melodía y la armonía}

Volviendo al toque, en el aspecto melódico, señalaremos que, por influencia del cante, la guitarra flamenca no suele utilizar intervalos disjuntos en sus melodías. Tanto en las falsetas como en las respuestas al cantaor, el "tocaor" suele utilizar melodías con intervalos conjuntos, es decir notas que se siguen en el orden de la escala, evitando los saltos. Sin embargo, recientemente sí podemos escuchar algunos intervalos disjuntos, uno de los recursos utilizado por el lenguaje guitarrístico de Paco de Lucía, con el propósito de destacar con ello una nota en especial. Esta nota puesta de relieve además por su acentuación, vendría a ser la traducción musical de lo que los aficionados llaman "pellizcos en el cante", es decir momentos cumbres de la expresión o emoción.

En el aspecto armónico, el toque parte de la armonización de los cuatro grados del archiconocido tetracordio descendente La Sol Fa Mi, con los acordes siguientes: La menor, Sol mayor, Fa mayor, Mi mayor.

Hemos visto que el primer papel que desempeña el guitarrista flamenco consiste en proporcionar acompañamiento al cante y baile, es decir producir acordes y ritmos sobre la melodía del cantaor. Con los acordes llamados también "posturas" por los tocaores ${ }^{8} \mathrm{o}$ "tonos" por los cantaores, aparece un concepto fundamental en la música elaborada: la armonía. Cabe recordar que la escritura de la melodía es horizontal, es decir que corresponde a sonidos emitidos sucesivamente. En el caso del cante y debido a sus particularidades, esta melodía será monódica, es decir interpretada a una sola voz, salvo el caso de algunos fandangos de Huelva, algunas sevillanas y recientemente estribillos en formas rítmicas como tangos, bulerías o alegrías. Al contrario, la escritura de la armonía es vertical, es decir que corresponde a varios sonidos emitidos simultáneamente.

\footnotetext{
8 A partir de ahora, dejaremos de entrecomillar este término propio del flamenco, considerando que ha quedado claro su significado de guitarrista flamenco.
} 
Cuando hablamos de los primeros acompañamientos, conviene ser extremadamente prudente, debido a la falta de documentación sonora, al tipo de información, informante, etc. que proporcionan datos sobre el tema. En este sentido y a título de ejemplo, recordaremos la documentada ponencia de Eusebio Rioja y Ángel Luis Cañete Díaz presentada en 1987 en el XV Congreso Nacional de Actividades Flamencas, en la cual desmontan algunas hipótesis de Antonio Mairena y Ricardo Molina y seguidores, aludidas en el estado de la cuestión de la introducción, sobre la no-presencia de la guitarra en la elaboración de algunos estilos actuales, llamados por ellos "primitivos" o "gitanos puros". Rioja y Cañete llegan a concluir, después de haber reforzado su convicción de que el flamenco es un arte romántico, que:

por tratarse el Arte Flamenco de una manifestación evolucionada y que parte en sus inicios del folclore andaluz ${ }^{9}$, que usaba generalizadamente guitarras en su interpretación, pensamos que este arte inició sus primitivas formas también acompañadas con este instrumento. Existen abundantes referencias literarias que así lo pintan (Rioja y Cañete, 1987).

En base a estas referencias literarias, afirman que los gitanos practicaban el toque de guitarra10, como instrumento favorito, del cual se valieron para elaborar las formas flamencas de carácter "hermético" (si es que fue asî) que ellos ${ }^{11}$ crearon (si es que las hubo).

\footnotetext{
${ }^{9}$ Llama la atención, en su apreciación, la ausencia de consideraciones sobre la influencia del colectivo gitano-andaluz en los orígenes del género flamenco. En efecto, como veremos en las fuentes de nuestra tesis, existen también abundantes referencias sobre el llamado "canto gitano" y/o a un tipo de interpretación asociado a esta etnia, que ¿intencionadamente? no recogen aquí.

${ }^{10}$ Como hemos visto en el estado de la cuestión, este aspecto no ha sido aún analizado con profundidad en los estudios sobre flamenco y sobre cultura gitana.

11 Este uso del sujeto "ellos", como opuesto al "nosotros", es significativo de la dicotomía cultural que anima el planteamiento de estos autores y que ha sido y sigue siendo habitual entre los aficionados al flamenco: andaluces versus gitanos, "payos" versus gitanos, o a la inversa, gitanos versus andaluces, gitanos versus "payos".
} 
Se puede contrastar esta tesis con el excepcional documento comentado por Arie C. Sneeuw (1991: 657-669)12 en la revista de flamenco Candil, sobre el flamenco "primitivo" o "pre-flamenco" descrito por el musicólogo y compositor belga François A. Gevaert, en su informe de 1852. El hispanista no duda en calificarlo como "el primer ensayo de análisis musical del flamenco y durante mucho tiempo -hasta la aparición del escrito de Falla de 1922- también el único que tengamos"13.

Además de la pertinencia de todas las descripciones musicales que coinciden con las de los demás músicos o musicólogos que se han acercado al arte flamenco (ver bibliografía), algunos como Rossy un siglo más tarde, Gevaert no dice nada sobre el acompañamiento de las melodías agrupadas con la denominación de cañas y playeras ya que «en cuanto a sus secuencias melódicas, la mayoría no comporta ningún género de armonía».

Sin embargo, aparece la guitarra en el otro grupo de melodías genéricamente llamadas aires de/danza (fandangos, malagueñas, rondeñas) para acompañar y destacar en los ritornelos instrumentales dónde «los guitarristas hábiles procuran lucir la agilidad de sus dedos y su facilidad para improvisar variaciones. Por consiguiente, suelen prolongar la duración del ritornelo más allá de la que tiene la copla». Lo que lleva a Sneeuw a concluir lo siguiente:

Vimos que el fundamento tonal del cante flamenco, tal como lo percibió Gevaert es el modo dórico, con marcada tendencia a determinado tipo de bitonalidad dórico/Mayor.

En este nivel no se diferenciarían cañas y playeras, por un lado, y fandangos, malagueñas y rondeñas, por el otro. Por otra parte, su descripción de cada uno de los sub-repertorios

12 Se trata de parte de las notas tomadas por Gevaert con motivo de su viaje a España de 1849 a 1851, viaje becado después de haber ganado el concurso nacional de composición musical de su país, Bélgica. No vamos a insistir sobre la importancia de unos de los primeros apuntes musicológicos sobre flamenco. Las citaciones de Gevaert y los comentarios siguientes de Sneeuw pertenecen al mencionado artículo.

${ }^{13}$ Sneew desconoce por lo visto el cancionero de Eduardo Ocón, publicado en 1874, y que contiene importantes informaciones que comentamos más adelante en el capítulo $6^{\circ}$. 
revela considerables discrepancias entre ellos. La más importante, ya que ella sola puede explicar todas las demás, es la inherente incompatibilidad con la armonía que en las cañas y playeras detectó el autor, incompatibilidad que éste relaciona directamente con el carácter primigeniamente no acompañado de estos cante ${ }^{14}$.

\section{Las descripciones de Gevaert confirman el modalismo"15 "arcaico" o} tradicional en el cual se basa parte del cante flamenco y plantea el problema de

\footnotetext{
${ }^{14}$ Gevaert realiza la siguiente clasificación del repertorio: a) Los cantes propiamente dichos, que se designan con el nombre de cañas o de playeras; b) Los aires de danza, que se denominan, según la localidad, fandangos, malagueñas o rondeñas; La descripción que hace de los cantos del primer grupo coincide con lo que Manuel de Falla llamaba "cante jondo", con la seguiriya gitana como cante rector.
}

${ }^{15}$ Término musical no recogido en los diccionarios de uso del español (muy parcos en términos musicales). Designa el uso de la modalidad (otro término musical tampoco recogido) como recurso diferente a la tonalidad. Recordamos que la palabra modalidad se refiere a los modos, es decir la diferente ordenación de las notas musicales, según la combinación de sus distancias, para formar una escala. Se habla de ocho modos de octava a octava desde la época griega: Dórico (Mi), Frigio (Re), Lidio (Do), Mixolidio (Si), Hipodórico (La), Hipofrigio (Sol), hipolidio (Fa), Hipomixolidio (Mi). Luego se suele referir a modos eclesiásticos medievales a los que, por un malentendido ocurrido en el siglo $X$, se les aplican los nombres griegos, sin tener nada que ver con los mismos. El modo Frigio griego Re por ejemplo, pasa a ser el Dórico gregoriano, el modo Dórico griego Mi pasa a ser el Frigio gregoriano, etc. Este embrollo ha producido confusión en la musicología que se ocupa de estudiar el flamenco, según la formación musical del musicólogo. El modo de Mi que fundamenta el flamenco es llamado Dórico por algunos autores (Rossy, Granados, Manolo Sanlúcar), en clara referencia a un hipotético origen griego de partida. Mientras los que defienden un origen modal medieval hablan de modo Frigio gregoriano (gran parte de la musicología clásica). El carácter descendente de la melodía flamenca (de agudo a grave), similar a la melodía griega en este aspecto, parece ser el argumento esgrimido para reivindicar este origen griego de partida. Al contrario, los modos gregorianos son ascendentes (de grave a agudo) y por consiguiente no reflejarían este carácter descendente de la melodía flamenca. La falta de documentación y de conocimiento sobre la antigua música de los griegos es el principal argumento que avanzan los defensores del origen medieval de este modo. Además, falta la documentación y demostración histórico-musicológica que pueda fundamentar los diferentes eslabones para explicar la permanencia de estas antiguas prácticas musicales de la época griega en pleno siglo XIX, cuando surge el género flamenco. A esta confusión hay que añadir otra, la de los músicos de formación jazzística. Este género utiliza la modalidad como parte de su lenguaje contemporáneo, y se adscribe a la denominación gregoriana, la más difundida, para designar los modos que utiliza. De esta manera, en el jazz el modo de Mi será Frigio, y por consiguiente el flamenco construido sobre este modo. La difusión internacional del jazz y de sus principios teóricos hace que, por lo común, entre la comunidad internacional de músicos, se hable de modo Frigio para el flamenco. Sin embargo, ante esta confusión, la musicología reciente que se ocupa de investigar sobre flamenco, aunque partiendo de una formación clásica, orientada más hacia la etnomusicología y sus metodologías sociales y culturales para estudiar las prácticas musicales en sus contextos, parece optar por el término "Modo flamenco" o "Modo de Mi flamenco", ya que este género se caracteriza, entre otras cosas, por usar de forma muy peculiar este modo de Mi. Cabe recordar por otra parte que, además de la modalidad, usada en el llamado repertorio "jondo", el flamenco utiliza la 


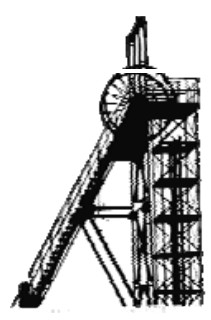

su armonización, es decir acompañamiento. La pregunta a contestar en la medida de lo posible sería ¿Cuándo, quién, dónde, cómo se realiza el encuentro de estas melodías modales con la guitarra?

Rossy señala que «el cante jondo, cuanto más sobrio y antiguo, se nos representa con mayor sencillez armónica. Hay cantes que para acompañarlos en la guitarra bastan dos acordes; para otros, bastan tres; y los más evolucionados necesitan de mayor ropaje armónico y emplean la llamada progresión armónica andaluza» (Rossy, 1966/1998: 86-87).

Todo tiende a indicar, como veremos más adelante, que parte del género flamenco es debido a la reunión de tres elementos dispares: unas melodías modales de tipo recitativo, unas secuencias rítmicas ternarias cíclicas amoldadas en compases llegados de ultramar como los de amalgama, unos acompañamientos de simples danzas ternarias con llamadas "cadencias andaluzas".

Parece ser que fueron los toques llamados "por arriba" y "por medio" los primeros utilizados para acompañar este tipo de melodías $^{16}$. Se suele argumentar que el primero está formado por el medio-tono entre los acordes MiM y FaM, el segundo por el semi-tono entre LaM y SibM. Tenemos aquí lo que Rossy denomina cadencias dóricas o cadencias flamencas, con cierto aspecto moderno al tener el tercer grado alterado del acorde resolutivo o de

tonalidad, es decir la evolución de los modos La (Eólico) y Do (Jónico) de donde saldrían en el siglo XVI nuestros actuales modos mayor y menor. La tonalidad y su desarrollo están inconfundiblemente ligados a la música en sentido vertical, es decir a la armonía, definiendo el "carácter de una melodía o pieza, como resultante de las mutuas relaciones de las notas de una escala entre sí con relación a una nota central (tónica) y dominante, en torno a las cuales se agrupan sus armonías como pivotes" (Pérez, 1985: 273).

16 Marín (1902/1995: 175) escribe en su método de 1902 que «la palabra tono, entre ellos [el tocaor y el cantaor] es el traste donde se pone la ceja artificial, y una vez colocada ésta en su sitio, sólo tienen dos nombres para diferenciar, y son, por medio y por arriba: medio, es la mayor y por arriba, la menor, ó mi mayor ó menor». Fernando de Triana (1986: 244) confirmará lo mismo después. 
tónica $\mathrm{Mi}$, desde que esta tercera empezó a valorarse para determinar la tonalidad (Rossy, 1966/1998: 83) ${ }^{17}$.

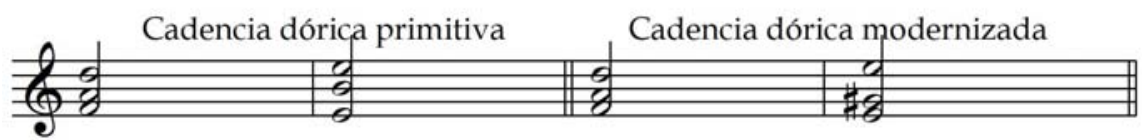

Imagen 1. Cadencia dórica primitiva y modernizada

Hay que precisar que los acordes llamados Fa y Sib por los tocaores no son tales, debido a la no-utilización de la cejilla con el dedo índice de la mano izquierda, y esto en la mayoría de los casos.

Esta falta de utilización de la cejilla en la posición de los acordes permite la presencia de la nota Mi dada por la primera cuerda al aire, nota pedal que sigue sonando mientras el guitarrista efectúa su progresión armónica. Esta cautela correspondería al carácter no armónico de algunas melodías del cante apuntado por Gevaert. Nos da una idea de las actitudes y juicios de los supuestos primeros guitarristas para elaborar el sistema musical propio de la estética flamenca.

La audición de los primeros registros sonoros hasta los toques actuales de concierto más elaborados permite observar que este uso constante de la nota Mi, obsesiva para el oído occidental, está siempre presente y constituye uno de los rasgos de la estética musical del flamenco (con las cadencias antes referidas, forma parte de aquellos elementos que el aficionado necesita escuchar, para reconocer lo que suena y lo que no suena flamenco). Debido a la afinación de la guitarra y a la presencia de esta nota en la prima, la guitarra aparece como el instrumento más idóneo para la ejecución de un singular sistema musical.

Si a ello añadimos la particular técnica de pulgar alternando con el índice en la mano derecha antes aludida, técnica que sigue siendo esencial en la

\footnotetext{
17 El Si de la cadencia primitiva queda reemplazado por Sol\#.
} 


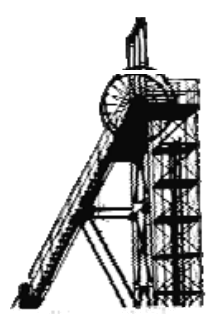

guitarra flamenca, vemos que esta repetición del Mi aparece también en las variaciones instrumentales o "falsetas".

Por otra parte, Gevaert habla de aires de danza, con la clasificación de fandangos, malagueñas o rondeñas. Su descripción no presta a confusión en cuanto al carácter bimodal ${ }^{18}$ y rítmico de los bailes:

La tonalidad es la misma que la de todos los aires españoles de origen árabe, es decir, que está basada en una escala que corresponde al tercer modo eclesiástico (...). Algunos intervalos se ven frecuentemente afectados de accidentes, ya que se dan transiciones muy bruscas a los tonos de do, de sol o de fa. La entrada de la copla, por ejemplo, se realiza siempre mediante una modulación que resulta de un efecto certero si es abordada limpiamente (...). Los aires de esta especie tienen, por lo común, un compás de $3 \times 4$ bastante vivaz.

Una vez más coincide con la clasificación de Rossy, quien dice lo siguiente sobre los cantes bimodales:

la numerosa familia de los fandangos es bimodal, por cuanto que la parte instrumental confiada a la guitarra está en modo dórico, la copla se manifiesta en modo mayor y en su último fragmento (la caída del último tercio, que dicen los flamencos) modula al modo dórico (Rossy, 1966: 100) ${ }^{19}$.

\footnotetext{
18 Que utiliza dos modos. En el caso del fandango, el modo frigio y modo jónico, este último generando el actual modo mayor.

${ }^{19}$ Cabe recordar que, según el modo, Rossy clasificaba los cantes en tres grandes grupos: a) cantes en modo dórico (escala griega en $\mathrm{Mi}$ ); b) cantes en modo mayor o modo menor; c) cantes bimodales. En el grupo a) incluía toná, canto de la trilla, saetas antiguas, saetas por seguiriyas, debla, seguiriyas gitanas, soleares, la caña, tientos, tangos flamencos, livianas, serranas, petenera, el vito, el olé, jaleo canastero, zorongo gitano. En el grupo b), martinete, carcelera, cabales, alegrías, mirabrá, romeras, boleros, garrotín jaleo de Jerez, tanguillo de Cádiz. En el grupo c), taranta, media taranta, tarantilla, taranto, cartagenera atarantada, cartagenera afandangada, fandangos, fandanguillos, verdiales, jabera, rondeña, malagueña, granaína y media-granaína, alicantina, cant de l'Horta de Valencia. Luego señalaba un grupo con modos dórico, mayor o menor constituido por las nanas, bulerías y sevillanas y un cante con modo mayor con final en la semi-cadencia del relativo menor, el polo (Rossy 1966/1998: 97-98). Como indica Sneeuw, Gevaert no menciona en 1850 el segundo grupo.
} 
Como hemos señalado antes, Gevaert menciona aquí las improvisadas y virtuosas variaciones de los guitarristas en los ritornelos instrumentales. ¿A qué guitarristas se refiere? El hecho de no dar ningún nombre deja suponer que se trata de intérpretes anónimos, populares. El repertorio debe de pertenecer al folklore musical y corresponde al éxito popular de un instrumento (la guitarra) y de un sistema musical basado en las llamadas escala y cadencia andaluzas que definen una estética no medible con los conceptos armónicos europeos de la época.

¿Melodías con ritmo muy poco determinado y tonalidad vaga, otras rápidas en compás de $3 \times 4$ y definidas armónicamente, folklore musical variado y estéticamente organizado, guitarristas virtuosos e improvisadores, quién pondrá orden en todo esto para que a finales del siglo XIX el arte flamenco sea una realidad palpable?

\subsection{Toques "por arriba" y "por medio"}

Después de esta introducción para plantear el problema de la armonía en los primeros acompañamientos, queremos volver a las formas comunes del toque y señalar ciertos aspectos musicológicos, fruto de nuestras observaciones y audiciones.

Aunque los toques "por arriba" y "por medio" corresponden a dos formas o maneras de interpretar la cadencia andaluza, conviene señalar que existen ciertas diferencias entre ambos.

Si la progresión armónica está clara en Mi con los acordes llamados Lam, Sol, Fa, Mi (IV, III, II y I grado del modo dórico griego o frigio gregoriano) por los tocaores, ésta no tiene la progresión armónica correspondiente cuando estamos en La. En lugar de tener Rem, Do, Sib, La, tendremos Sib, Do7/9, Sib (o Solm), La. Pensamos que esta diferencia es debida en primer lugar a la mayor dificultad técnica de la mano izquierda para realizar los acordes "por medio", lo que ha llevado a los tocaores a buscar posiciones más cómodas. 


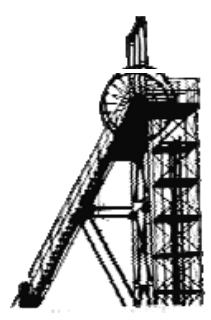

Luego esta progresión permite mantener dos notas (sib y re) en los tres primeros acordes y dar la sensación de oír dos acordes en lugar de cuatro.

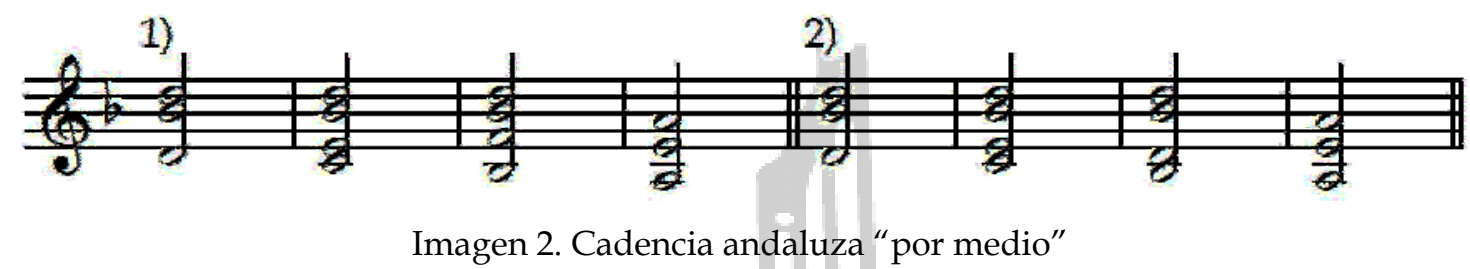

Vemos cómo la cadencia llamada andaluza consiste en este caso en tocar los bajos Re, Do, Sib, sobre el acorde Sib y concluir con La:

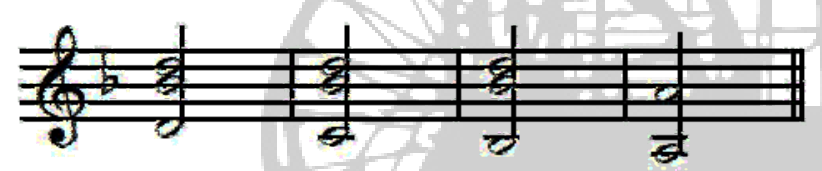

Imagen 3. Cadencia andaluza "por medio"

El segundo acorde, Do7/9, es realmente una prueba de la genialidad musical de los tocaores. Consiste en mezclar el III grado o "tono", es decir DoM, con el II, Sib. ¡Y es que acompaña perfectamente una melodía que sale del ámbito del Sib pero que no alcanza el Do! Además, es más fácil de tocar y enlazar con la posición del Sib. Vemos como, ante el problema de acompañar melodías no occidentales y de armonía indeterminada, los tocaores han sabido encontrar intuitivamente acordes con disonancias como la séptima o la novena, para resolver el acompañamiento.

Estas peculiaridades del toque "por medio" con respecto al toque "por arriba", hacen que los cantaores lo prefieren para el acompañamiento de los estilos "primitivos", tal como revela la audición de grabaciones antiguas de discos de pizarra de los primeros años del siglo XX. Será la forma establecida para acompañar por seguiriyas, pero también por soleá, tangos, bulerías en muchos casos, y por fandangos cuando el cantaor querrá más "hondura" en el toque. 
Los cantaores con rasgos étnicos marcados como los gitanos lo encontrarán más adecuado a su tipo de voz e interpretación, frente al toque "por arriba", de cierto colorido folclórico y mayor precisión armónica.

Es un tipo de toque muy cultivado en lugares de tradición flamenca, como Jerez de la Frontera, donde mejor se conserva en su estado sencillo de dos acordes. Es asombroso observar cómo la semi-cadencia Do7/FaM en este toque, tan empleada ahora, tocaores como los hermanos Jero la resuelven con el tradicional Do7/9, Sib sin que el oído sea molestado (los acompañamientos de bulería y bulería por soleá conservan también una sencillez original difícilmente localizable en otras ciudades).

\subsection{Toques derivados}

A partir de transposiciones de la armonización de la cadencia andaluza pues, los guitarristas han establecido varios toques, cada uno con su color característico. A partir de la nota Mi dada por la sexta cuerda al aire, el toque llamado "por arriba": La menor, Sol mayor, Fa mayor, Mi mayor. A partir de la nota La dada por la quinta cuerda al aire, el llamado toque "por medio": Re menor, Do mayor, Sib mayor, La mayor. A ello, se añadieron otros. A partir de la nota Si dada por el segundo traste de la quinta cuerda, el llamado toque "por granaina": Mi menor, Re mayor, Do mayor, Si mayor. A partir del segundo traste de la sexta cuerda, el llamado toque "por Levante": Si menor, La mayor, Sol mayor, Fa\# mayor.

El guitarrista Ramón Montoya, además de tener cierta influencia en la estabilización definitiva de estas transposiciones por su trabajo artístico con el cantaor Antonio Chacón, las ha ampliado con otras dos: a partir del cuarto traste de la quinta cuerda, desafinando dos cuerdas, con el llamado "toque por rondeña": Fa menor, Mi mayor, Re mayor, Do\# mayor, a partir del cuarto traste de la sexta cuerda, con el llamado toque "por minera": Do\# menor, Si mayor, La mayor, Sol \# mayor. 


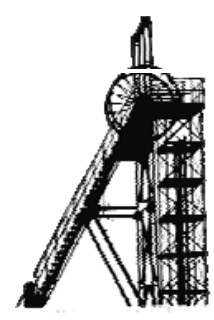

Vamos a detenernos a continuación en estos toques y verificar si presentan "anomalías" como la que hemos oído en el toque "por medio". Empezaremos por el de granaína.

\subsubsection{Toque "por granaína"}

Aunque como acabamos de ver, los tocaores han utilizado solamente dos toques para los primeros acompañamientos del flamenco, "por medio" y "por arriba", hay un tercer toque que también está documentado a mediados del XIX, el conocido como "toque de granaína". En efecto, el compositor y folclorista malagueño Eduardo Ocón recopila materiales populares andaluces entre 1854 a 1867 (Martín Tenllado: 1991, 181-194) para publicarlos en 1874 (Ocón: 1888) -donde describe por cierto como veremos más adelante varias formas de rasguear y nos informa indirectamente del alto grado de tecnicidad alcanzado- y transcribe tres formas de marcar la cadencia andaluza: "por medio" que aplica al acompañamiento de fandangos, "por arriba" para las malagueñas y rondeñas, y con el medio-tono /DoM/Si7 en el acompañamiento de murcianas o granadinas. Por los datos analizados hasta ahora, parece que esta última forma no era practicada en Andalucía Occidental, y sí utilizada en la parte oriental y levantina en fandangos llamados murcianas y granadinas. A diferencia de los demás toques, utiliza una disonancia (la $7^{\mathrm{a}}$ ) en el acorde de primer grado. Servirá más tarde en la primera mitad del siglo XX para acompañar los llamados estilos de media-granaína y granaína y a finales del XIX los de Levante en un primer momento, que tendrán después su propio "toque por Levante" o "por taranta", con el uso de varias disonancias también en el acorde de 1er grado. Otra diferencia que tiene este toque y que explica en parte el carácter lírico y melismático ${ }^{20}$ del cante correspondiente, es que oscila entre el modo flamenco y el modo menor, en este caso Mi menor. Mientras los otros concluyen en el acorde de dominante de la tonalidad menor homónima, el

\footnotetext{
${ }^{20}$ Neologismo no recogido en los diccionarios de uso del español, muy utilizado en los libros que tratan sobre música. Que utiliza melismas, es decir grupo de notas cantadas sobre una misma vocal.
} 
de granaína concluye con la tónica del modo menor. El toque flamenco ha sido claramente elaborado a partir del acompañamiento folclórico como veremos más adelante, (lo que confirma nuestra hipótesis de trabajo en este caso), pero con algunas modificaciones. Entre ellas está la substitución del acorde Si7 que inicia y concluye la cadencia andaluza correspondiente, por otro con una disonancia aún mayor, un intervalo de segunda menor entre la primera y segunda cuerda:

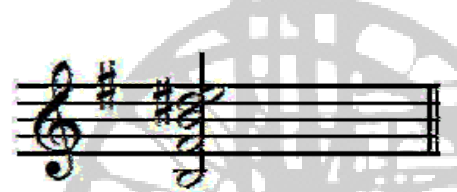

Imagen 4. Acorde final en el toque por granaína

De nuevo, vemos que la particularidad organológica de la guitarra, con la primera cuerda afinada en $\mathrm{Mi}$, provoca una disposición armónica peculiar en el uso de una no menos particular disposición de los acordes por parte de los tocaores, que confiere a los toques flamencos un carácter musical vanguardista con respecto a la evolución armónica de la música en la misma época ${ }^{21}$. Esta armonía, que podemos calificar de idiomática ya que emana de las propias características de la guitarra y del uso que hacen los tocaores, será la del flamenco como género musical.

\subsubsection{Toque "por Levante" o "por taranta", "por minera" y "por rondeña"}

Rafael Marín no recoge el toque “por Levante" en su método de 1902, lo que indica que, caso de utilizarse ya, no estaba difundido entre los profesionales, por lo que podemos afirmar que se trata de un toque que ha sido elaborado a principios del siglo XX.

\footnotetext{
${ }^{21}$ Manuel de Falla (1950/1972: 75). escribirá sobre ello, refiriéndose a Claude Debussy, que «hay todavía un hecho interesante sobre ciertos fenómenos armónicos que se producen en el particular tejido sonoro del maestro francés. Estos fenómenos en germen los producen en Andalucía con la guitarra de la manera más espontánea del mundo. Cosa curiosa: los músicos españoles han descuidado, incluso desdeñado, estos efectos, considerándolos como algo bárbaro o acomodándolos a los viejos procedimientos musicales; Claude Debussy les ha mostrado la manera de servirse de ellos. Las consecuencias han sido inmediatas: basta para demostrarlo las doce admirables joyas que bajo el nombre de Iberia nos legó Isaac Albéniz».
} 


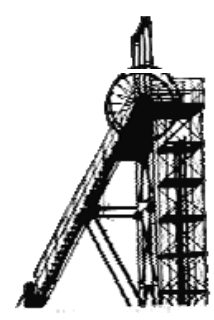

Aunque algunos autores dudan en atribuir la creación a Miguel Borrull (padre) o Ramón Montoya (Gamboa, 1992), lo que sí está claro es que la figura de Antonio Chacón y su popularización de los estilos mineros han contribuido a su difusión y consolidación entre los profesionales y aficionados. Resulta sintomático que Miguel Borrull y Ramón Montoya hayan sido precisamente los dos tocaores principales que acompañaron a Chacón a finales del siglo XIX y principios del XX, y que haya sido Montoya el que grabara de forma ya bien definida este toque como acompañamiento de los estilos mineros con Antonio Chacón en 1913.

El procedimiento inicialmente parece sencillo. Al tener que acompañar estilos de la familia de la malagueña, acompañados habitualmente con el toque "por arriba", y al tener el cantaor una tesitura de voz más aguda, el hipotético tocaor transporta el acorde de tónica Mi del toque "por arriba" un tono más alto, y lo coloca dos trastes más arriba. (Lo que parece extraño en este caso, es que no utilizara la cejilla, bien difundida ya entre los tocaores para acompañar a los cantaores ante estos problemas de tesitura). Supongamos que nuestro hipotético tocaor no tenga este día cejilla para acompañar cómodamente, por lo que tenga que hacer esta operación de transporte sin este aparato. Una vez colocada la mano en el segundo traste, poder acompañar el cante en esta posición resulta incómodo ya que no es una "postura" natural en la guitarra, y por eso requiere, a defecto de la ausencia de la cejilla mecánica, usar la otra, la del dedo índice de la mano izquierda que pisa todas las cuerdas. Utilizar constantemente esta cejilla física resulta incómodo para la mano, ya que se trata de una posición crispada que pronto le cansará y agarrotará. Para relajarla, será necesario dejar de hacer la cejilla en todas las cuerdas con el índice, que solo pisará la sexta cuerda. Aunque parece una operación de ergonomía musical elemental ${ }^{22}$, armónicamente el resultado será muy diferente:

\footnotetext{
22 Sobre la ergonomía musical aplicada a la guitarra, se puede consultar el librito del profesor médico Joaquín Farias (2005) y el tratado pedagógico de Virginia Azagra (2006).
} 
$\begin{array}{ll}\text { 1) Acorde sin cejilla } & \text { 2) Acorde con cejilla }\end{array}$

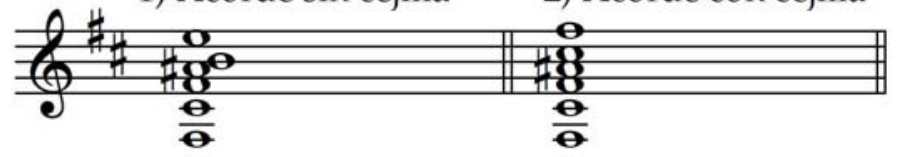

Imagen 5. Posibilidades del acorde de I grado en Fa\# frigio

El acorde sin cejilla presenta dos notas extrañas a la armonía o disonancias, la séptima Mi dada una vez más (qué coincidencia) por la primera cuerda al aire y la nota si (segunda cuerda al aire) que, debido a su posición en la escritura vertical, adquiere el nombre de oncena. Rossy dirá sobre ello que:

precursores de Vincent d'Indy, Debussy y Falla, (los guitarristas gitanos) obtienen efectos armónicos que enriquecen la música popular de Andalucía y Levante con las atrevidas concepciones de la armonía moderna (Rossy, 1966/1998: 89).

El acorde tiene además la particularidad de presentar un intervalo de segunda menor (La\# Si), prohibido entre otras cosas por la armonía clásica. Tocado solo resulta inaudible, pero así con todo el acorde estructurado, da un colorido muy peculiar que sugiere con un poco de imaginación, la sensación de escuchar un cuarto de tono. Veremos más adelante que a partir de este momento, la segunda menor será una constante en la armonía del toque, y uno de los recursos utilizados en la estética musical del flamenco. ¿Intento por parte del guitarrista de reflejar con la armonía una de las particularidades del cante?

Con el acorde de oncena, se puede hablar de indefinición tonal. Quizá la respuesta de los tocaores ante el problema surgido por melodías con rasgos particulares, entre otros, la difícil compatibilidad con la armonía. Pero hay más.

Si el acorde 1) es el que podemos escuchar en las primeras grabaciones y el que recoge Rossy en su tratado teórico, los tocaores han aportado hoy una modificación, levantando simplemente el dedo medio de la mano izquierda, transformando el La\# en Sol. 


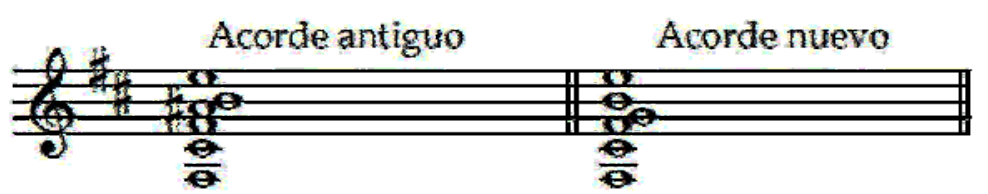

Imagen 6. Acorde de tarantas

Esta simple cuestión técnica, con toda seguridad para ejecutar una introducción en ligados con los dedos índice-medio en la sexta cuerda que pasó a ser la forma de anunciar el toque "por Levante", tiene varias consecuencias.

Al desaparecer el La\# desaparece el intervalo de tercera mayor que determinaba el modo mayor del acorde de dominante. Al tener la tercera cuerda al aire, resultará claramente en las tres primeras cuerdas un acorde de Mi menor en su primera inversión. Seguimos teniendo un intervalo de segunda menor, es decir disonante, esta vez entre las notas Fa\# y Sol. Volviendo al acorde de oncena anterior y a su carácter bimodal o tonalidad indefinida, tenemos ahora un acorde menor definido (Mi) y un acorde mayor no definido (Fa\# sin la tercera que determina el modo), pero sí asimilado como mayor en la cultura musical flamenca que espera siempre un acorde mayor como conclusivo de la cadencia andaluza. El resultado es por consiguiente la superposición de dos acordes: uno mayor sugerido, y otro menor definido.

Con esta relación tonal encontramos uno de los toques más bellos que los guitarristas flamencos han podido desarrollar como son los de taranta y taranto.

Buscando el acoplamiento del toque de Levante con una voz aguda, según nos informa Manuel Cano, Ramón Montoya adapta la cadencia andaluza con la secuencia armónica Do\#m, SiM, LaM y Sol\#M:

La dificultad que supone para un guitarrista el acompañamiento y el encontrar la justa tonalidad de las voces muy agudas en los tonos tradicionales, hace que la gran sabiduría de Ramón Montoya adopte un tono nuevo en la guitarra, SOL SOSTENIDO, con lo cual en una misma posición de la cejilla o "capodastro" 23 dentro de la división o traste se ha

${ }^{23}$ Italianismo introducido en el uso de los guitarristas españoles como sinónimo de cejilla. Al designar la palabra española "cejilla" tanto el dedo índice que pisa varias cuerdas, como el 
conseguido subir un tono a la tonalidad normal de la taranta: FA SOSTENIDO, encontrándose los tonos relativos a las distintas modulaciones exigidas en el desarrollo de los tercios del cante, en posiciones normales y tan fáciles como pueden ser MI SÉPTIMA-SI MAYOR o LA MAYOR (Cano, 1987: 228)24.

Examinando de cerca esta relación armónica aplicada a la guitarra y en la forma que la ejecutan los tocaores, vemos que permite la utilización frecuente del intervalo de segunda menor, dado una vez más por la nota pedal Mi en la primera cuerda. También Montoya procura alternar la posición normal Sol\#M con cejilla al cuatro, con otra posición en el primer traste que permite el intervalo de segunda menor en los bajos. Vemos por consiguiente que ha asumido musicalmente la segunda menor como colorido del toque de Levante y busca su relación en la elaboración de nuevos toques, en este caso el que grabará como solista con el nombre de "minera" 25.

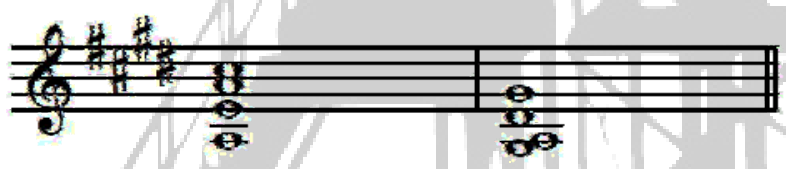

Imagen 7. Acordes conclusivos en el toque por mineras

Por las varias disonancias que permite, particularmente el intervalo de medio tono o segunda menor, es en la actualidad uno de los más interpretados por los concertistas actuales, que encuentran en su armonía la posibilidad de elaborar falsetas que suenen nuevas.

aparato que se coloca en el mástil para esta misma función, este italianismo deja claro de que se trata del aparato.

${ }^{24}$ La voz es la de José Cabello Luque "Chaconcito" (Aguilar de la Frontera (Córdoba), 1915-¿?), joven cantaor que con diez años mendigaba por el barrio Vallecas de Madrid, recogido por el tocaor Marcelo Molina y contratado después por el empresario Vedrines, actuando entre 1926 y 1932 en los teatros y cines madrileños. Según Blas Vega y Ríos Ruiz, fue un destacado imitador de las figuras de la época, entre ellas como su nombre artístico indica, Antonio Chacón (Blas Vega y Río Ruiz, 1988: 234).

${ }^{25}$ Ramón Montoya grabó el toque de minera en Paris en una serie de seis discos de $30 \mathrm{~cm}$ en el sello BMA (La Boîte à Musique), entre el 21 y 22 de octubre, con lo que hoy llamaríamos "producción" de Marius de Zaya. Estos discos aparecieron en el catálogo de la BMA con el título genérico de "Arte Clásico Flamenco" entre "Orfeo" de Monteverdi y el "Clavecino bien temperado" de J.S. Bach. Otro toque célebre que quedó registrado en esta memorable grabación de guitarra flamenca de concierto fue el de rondeña. 


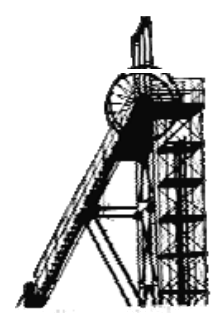

La estética de Levante será una de las predilectas de Ramón Montoya, quien establecerá un último toque para concierto, el de rondeña, sin que tenga relación con el estilo de cante con el mismo nombre. La rondeña es una pequeña composición para guitarra flamenca solista que utiliza una afinación especial prestada del laúd renacentista, desafinando medio-tono la tercera cuerda, que pasa de Sol a Fa\#, y la sexta cuerda un tono, que pasa de Mi a Re. Ramón Montoya la grabó en 1922 y 1936 y se ha mantenido como toque de concierto, hasta la época que hemos calificado de "contemporánea", en la que entre otros recursos para redefinir el código de las reglas estéticas del flamenco, se utiliza este toque para cualquier estilo, sea rítmico o libre.

\subsection{Toques en tonalidades mayor y menor}

Además de estas transposiciones, el guitarrista se ha valido de una armonización clásica en tonalidades mayores y menores, con los acordes de Tónica, Dominante y Subdominante, para acompañar estilos de más reciente incorporación en el repertorio flamenco, como la familia de las cantiñas (alegrías, romera, mirabrá, caracoles) o los llamados estilos de " ida y vuelta" (guajira, colombiana, milonga, vidalita, rumba). Las tonalidades elegidas han sido las más eficientes para la guitarra, dada su afinación: Do mayor, Re mayor, La mayor, Mi mayor, y las tonalidades menores de La, Re y Mi. Por el uso cómodo de cuerdas al aire que permiten, estas tonalidades son en efecto las predilectas en la guitarra de cualquier género. Tendremos así los acordes de Do mayor (tónica), Sol7 (dominante) y Fa mayor (subdominante) si la tonalidad utilizada es la de Do mayor, por ejemplo, en el acompañamiento actual de las cantiñas. De la misma manera tendremos La menor (tónica), Mi7 (dominante) y Re menor (subdominante) si la tonalidad empleada es la de La menor, por ejemplo, en el acompañamiento de farruca. 


\section{Bibliografía}

AzAGRA, Virginia (2006). La salud del guitarrista. Guía para estudiar sin esfuerzo, prevenir lesiones y mejorar el rendimiento. San Lorenzo del Escorial (Madrid): Acordes Concert.

Blas VegA, José y Ríos RuIZ, Manuel (1988). Diccionario Enciclopédico Ilustrado del flamenco. Madrid: Cinterco.

CANO TAMAYO, Manuel (1986) La guitarra. Historia, Estudios y Aportaciones al Arte Flamenco. Córdoba: Universidad de Córdoba y Monte de Piedad y Caja de Ahorros de Córdoba.

CASTRO, María Jesús (2007). Historia musical del flamenco. Barcelona: Casa Beethoven Publicacions.

CRISTOFORIDIS, Michael (1993). Manuel de Falla y la guitarra flamenca. La Caña. Revista de Flamenco. Madrid: Asociación Cultural España Abierta.

CRUCES, Cristina (2000). El flamenco. Conocer Andalucía. Gran Enciclopedia del Siglo XXI. Tomo 6. Cultura Andaluza. Sevilla: Tartessos.

FALlA, Manuel de 1950/1972. Escritos sobre música y músicos. Madrid: Espasa Calpe, Madrid.

FARIAS, Joaquín (2005). Técnica de la guitarra flamenca. Guía práctica de ergonomía musical. Biomecánica y prevención de lesiones. Sevilla: Ediciones Galene.

Gallardo, José María (1997). La estética del toque. XXIV Congreso de Arte Flamenco. Actas. Sevilla: Fundación Machado.

GAmBOA, José Manuel (1992). La guitarra flamenca. La Caña. Revista de flamenco, $n^{\circ} 3$, junio, Madrid: Asociación Cultural España Abierta.

GAmbOA, José Manuel y Núñez, Faustino (2007). Flamenco de la A a la Z. Diccionario de términos del flamenco. Madrid: Espasa.

LARREA, Arcadio de (1975). Guía del flamenco. Madrid: Editora Nacional.

MARín, Rafael (1902/1995). Método de guitarra por música y cifra. Aires Andaluces. Córdoba: Ediciones La Posada (edición facsímil).

Martín Tenllado, Gonzalo (1991). Eduardo Ocón: el nacionalismo musical. Málaga: Ediciones Seyer.

NúÑEZ, Faustino (1996). Los estilos flamencos. Navarro, José Luis y Ropero, Miguel, Eds. Historia del flamenco. Sevilla: Tartessos.

NúÑEZ, Faustino (2003). Comprende el flamenco. Madrid: R.G.L.

NúÑEZ, Gerardo (2004). La guitarra flamenca de Gerardo Núñez. Meilen (Switzerland): Encuentros Productions. 


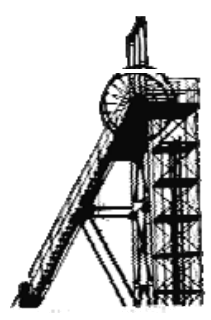

OCón, Eduardo (1879/1888). Cantos Españoles. Colección de aires nacionales y populares, formada e ilustrada con notas explicativas y biográficas (edición del autor). Málaga.

PÉreZ, Mariano (1985). Diccionario de la Música y los Músicos. Madrid: Istmo.

RAMADA, Manuel (2000). Atlas de percusión. Valencia: Rivera Editores.

RIOJA, Eusebio y CAÑETE, Ángel Luis (1987). La guitarra en los primeros tiempos del flamenco (I). Actas del XV Congreso de Arte flamenco. Estepona (Málaga).

ROPERO, Miguel (1984). El léxico andaluz de las coplas flamencas. Sevilla: Alfar.

RossY, Hipólito (1966/1998). Teoría del Cante Jondo. Barcelona: Credsa.

SANLÚCAR, Manolo (2005). Sobre la guitarra flamenca. Córdoba: Ediciones La Posada.

SNEEUW, Arie C. (1989). Flamenco en el Madrid del XIX. Córdoba: Virgilio Márquez Editor.

SNEEUW, Arie C. (1991). El flamenco descrito en 1850 por François Gevaert. Candil. Revista de Flamenco. Jaén: Peña flamenca de Jaén.

TORRES CORTÉs, Norberto (2004). Guitarra flamenca, volumen II. Lo contemporáneo y otros escritos. Sevilla. Signatura.

TORRES CORTÉs, Norberto (2009). De lo Popular a Lo Flamenco. Aspectos Musicológicos y Culturales de la Guitarra Flamenca (Siglos XVI-XIX) (tesis doctoral). Almería: Universidad de Almería.

TRIANA, Fernando de (1935/1985). Arte y Artistas Flamencos. Madrid: Editoriales Andaluzas Unidas.

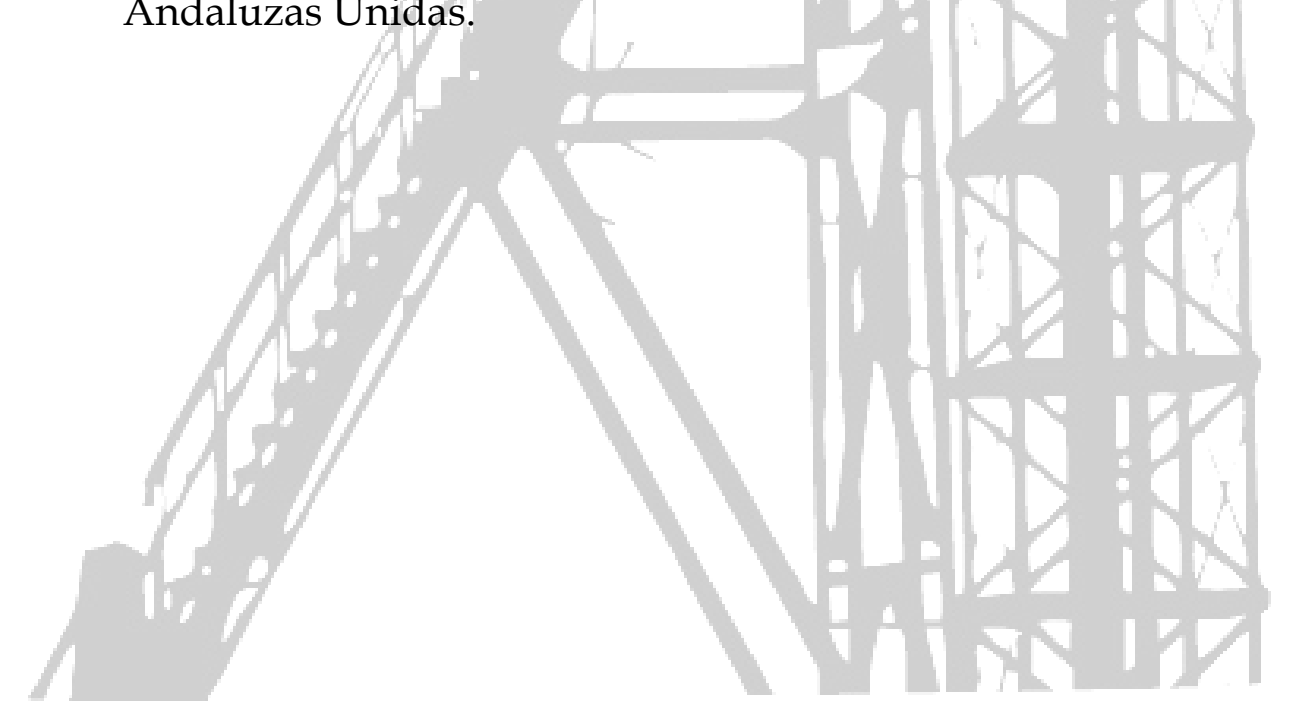

